\title{
Reduced Anterolateral Thigh Flap Donor-Site Morbidity Using Incisional Negative Pressure Therapy
}

\author{
Gunther Mangelsdorff, MD ${ }^{1}$ Pedro Cuevas, $\mathrm{MD}^{2}$ José Ramón Rodriguez, $\mathrm{MD}^{1}$ \\ Nicolás Pereira, MD, MSc ${ }^{1}$ Enrica Ramirez, MD $^{2}$ Ricardo Yañez, MD $^{3}$
}

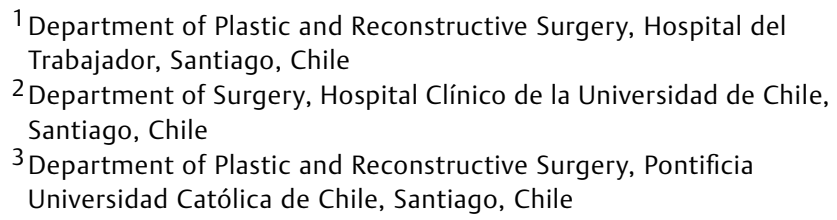

Address for correspondence Günther Mangelsdorff, MD, Department of Plastic and Reconstructive Surgery, Hospital del Trabajador, Ramón Carnicer North 185, Quinto Piso, Providencia, Santiago, Chile (e-mail: gmangels@gmail.com).

J Reconstr Microsurg 2019;35:229-234.

\begin{abstract}
Background Primary closure of the donor-site after harvest of a large anterolateral thigh flap (ALT) is associated with significant morbidity. Incisional negative pressure therapy (INPT) may decrease complications in high-risk incisions. This study assessed if the incidence of complications after primary closure of the ALT flap donor-site decreases with INPT.

Methods Retrospective cohort study of a prospectively maintained database including patients who underwent upper and lower limb reconstruction, using an ALT free flap with primary closure of the donor-site. Two groups were defined: primary closure and INPT (study group) and primary closure with traditional dressings (control group). Nonparametric statistics were employed to identify prognostic factors, $p<0,05$.

Results Fifty-eight free ALT flaps in 58 patients (study group $n=28$; control group $n=30$ ) were included. Median flap width and length were $9 \mathrm{~cm}$ (range: $5-14$ ) and

\section{Keywords}

- incisional negative pressure therapy

- anterolateral thigh flap

- complications

- free flap

- microsurgery

- donor site $25 \mathrm{~cm}$ (range: 10-48), respectively. Median follow-up was 19 months (range: 3-78 months). No significant differences in age or flap size were identified in both groups $(p>0.05)$. The global complication rate was $7.14 \%(n=2)$ in the INPT group, and $37 \%$ $(n=11)$ in the control group $(p=0.007)$. The study group had a lower dehiscence and skin necrosis rate $(p<0.05)$. Multivariate logistic regression analysis showed IPNT was associated with a significant reduction of donor-site complications $(p=0.006)$, especially in patients with defects $>8 \mathrm{~cm}(p=0.003)$.

Conclusion In this cohort study the use of INPT significantly reduced the donor-site morbidity after ALT flap harvest.
\end{abstract}

The free anterolateral thigh flap (ALT) is widely recognized as a workhorse flap in reconstructive microsurgery. ${ }^{1}$ Primary closure of the donor-site usually gives an adequate cosmetic result with minimal morbidity. However, harvest of larger flaps is increasingly related to donor-site complications or may require use of split thickness skin grafting, producing significant scarring (-Fig. 1). ${ }^{2}$ When primary closure is done under excessive tension, it can lead to numerous complications

received

March 27, 2018

accepted after revision

August 9, 2018

published online

September 27, 2018 including wound dehiscence, skin necrosis, seroma, and infection (-Fig. 2). Several experimental reports show that incisional negative pressure therapy (INPT) improves the microcirculation and also decrease tension across the suture. ${ }^{3}$ Furthermore, there is clinical evidence, which suggests that INPT may reduce the incidence of complications in wounds closed under tension, like mastectomy flaps or the donor-site of the superficial circumflex iliac artery perforator flap. ${ }^{4,5}$
Copyright $\odot 2019$ by Thieme Medical Publishers, Inc., 333 Seventh Avenue, New York, NY 10001, USA. Tel: +1(212) 584-4662.
DOI https://doi.org/ 10.1055/s-0038-1672126. ISSN 0743-684X. 

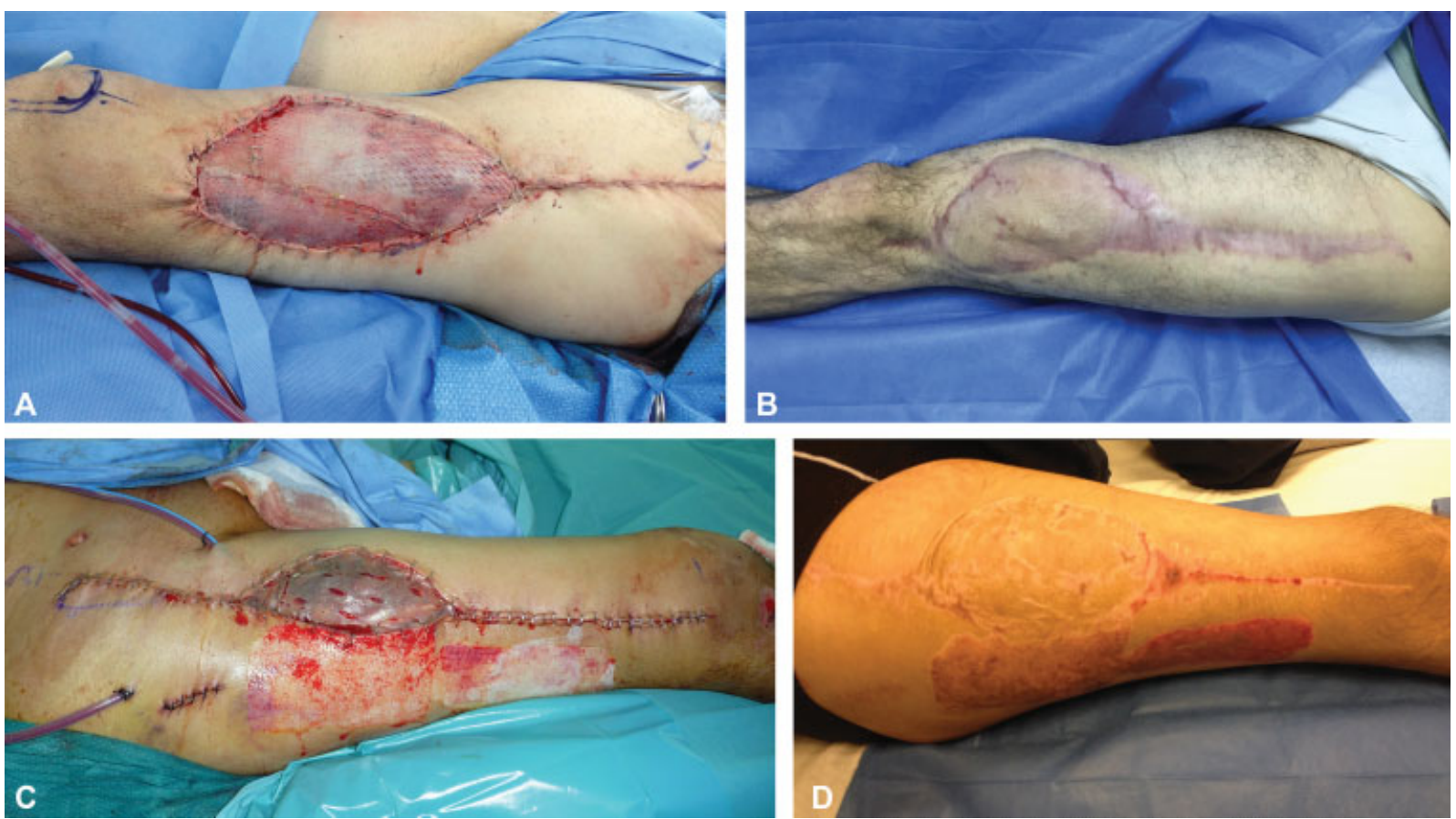

Fig. 1 Anterolateral thigh flap donor-site appearance after skin grafting. (A) Intraoperative view with meshed skin graft; (B) Six months postoperative result; (C) Intraoperative view with fenestrated skin graft; (D) Six months postoperative result.

The objective of this study is to evaluate if the use of INPT reduces the incidence of complications after primary closure of the ALT flap donor-site.

\section{Methods}

After institutional review board approval, we conducted a retrospective cohort study from a prospective maintained database of patients operated between 2009 and 2016, both groups were intervened in the same period of time. Patients who underwent upper and lower limb reconstruction using an ALT free flap with primary closure of the donor-site were included. Patients who required skin grafting of the donorsite were excluded from this study. All participants correspond to a captive population, which is beneficiary of a national work-related injury insurance that provides life-long medical assistance and economic compensation for injuries caused by work-related accidents or occupational illnesses.
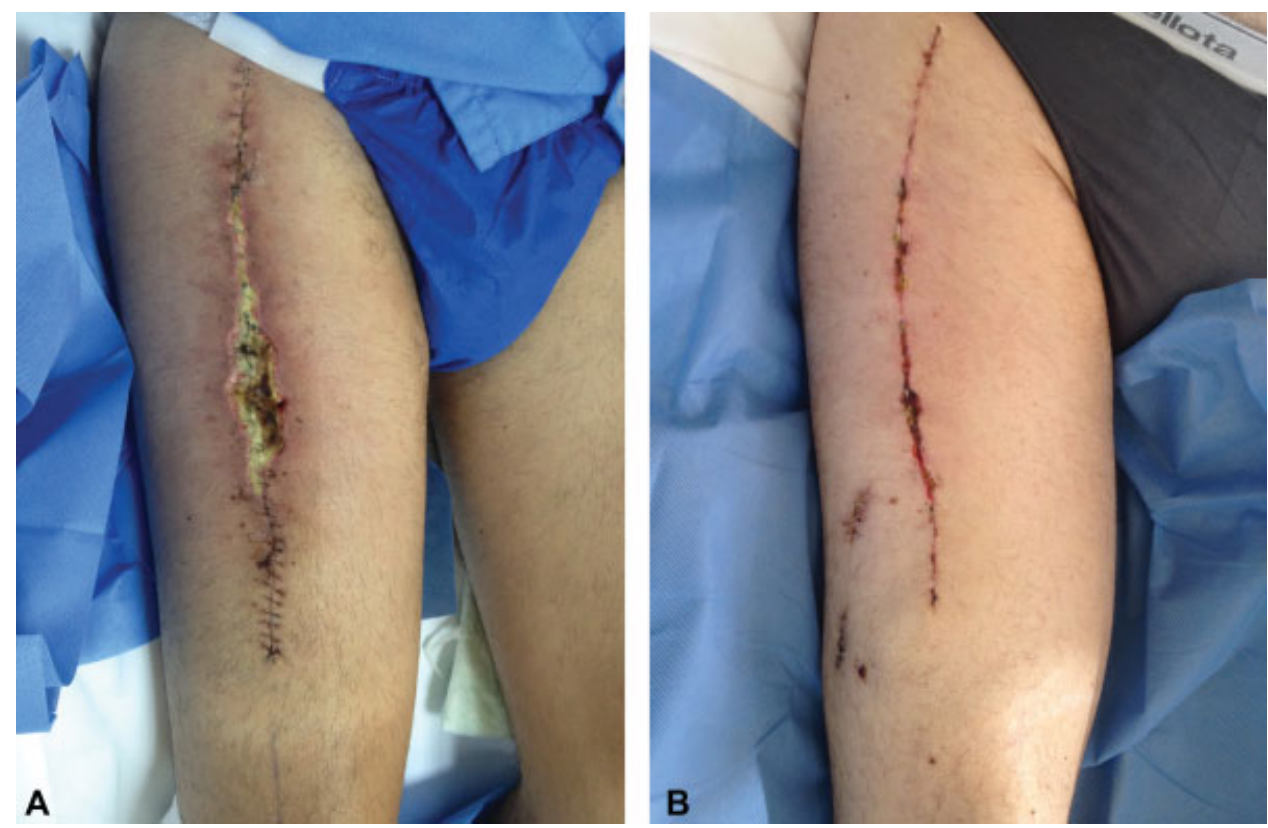

Fig. 2 Anterolateral thigh free flap donor-site complications after primary closure: (A) Skin necrosis and dehiscence; (B) Wound dehiscence. 
Patient demographic data and intraoperative details regarding type and size of the flaps were collected for analysis. Postoperative donor-site complications were prospectively recorded. During hospital stay, wounds were inspected on a daily basis. After discharge patient followup included a weekly visit for the first month, then monthly for the first 6 months and then every 3 months for at least 1 year.

Two groups were defined: primary closure with traditional dressings (control group), and primary closure of the donor-site and INPT (study group). In general, the control group was the historical group, the first patients intervened in the series, prior to the use of the INPT. Both incision care methods were performed over the entire study period.

For the performance of an ALT, patients with a BMI (body mass index) $>25$ were excluded, that is, no patient in the series was obese or overweight.

\section{Surgical Technique and Incisional Negative Pressure Therapy}

Primary closure of the ALT donor-site was performed in two or three layers, depending on the feasibility to close the deep fascia, using 1-0 Vicryl (Ethicon; Sommerville, New Jersey) for the fascial layer, 1-0 Vicryl for the subdermal plane, and an intradermal suture of 3-0 Vicryl (Stratafix, Johnson \& Johnson). A suction drain was left in place in all the cases. In the control group, wounds were covered with gauze and a paper tape dressing (Micropore, $3 \mathrm{M}$ ). In the study group, INPT was installed immediately after wound closure (Renassys; Smith and Nephew, London). The polyurethane foam of the negative pressure therapy device was placed in direct contact with the wound. Adjacent skin to the wound edges was protected from contact with the foam using a cutaneous protective film (Cavilon) and a layer of adhesive drape. Therapy was set at a pressure of $(-)$ $120 \mathrm{~mm} \mathrm{Hg}$ in continuous mode for 7 days, after which it was changed to a traditional dressing. INPT installation procedure is detailed in -Video 1.

\section{Video 1}

Intraoperative INPT installation procedure. Online content including video sequences viewable at: https:// www.thiemeconnect.com/products/ejournals/html/ 10.1055/s-0038-1672126.

\section{Statistical Analysis}

Data were analyzed using the SPSS software version 21.0 using nonparametric tests. Values were expressed in medians (Q1-Q3) and results between both groups were compared using the Fisher test and $U$ Mann-Whitney test. Logistic regression analysis was employed to determine prognostic factors and $p<0.05$ was considered statistically significant. All patients gave informed consent to participate in this study.
Table 1 Characteristics of patients treated with an ALT free flap and primary closure of the donor-site $(n=58)$

\begin{tabular}{|l|l|l|l|}
\hline & $\begin{array}{l}\text { Control group } \\
(\boldsymbol{n}=30) \\
(\mathrm{Q} 1-\mathrm{Q} 3)\end{array}$ & $\begin{array}{l}\text { INPT } \\
(\boldsymbol{n}=\mathbf{2 8}) \\
(\mathrm{Q} 1-\mathrm{Q} 3)\end{array}$ & -Value \\
\hline Age $(\mathrm{y})$ & $42.5(33-53)$ & $38(28-56)$ & NS \\
\hline Width $(\mathrm{cm})$ & $8(7-10)$ & $9(8-10)$ & NS \\
\hline Length $(\mathrm{cm})$ & $21.5(18-27)$ & $25(21.5-30)$ & NS \\
\hline Area $\left(\mathrm{cm}^{2}\right)$ & $\begin{array}{l}155.4 \\
(132-224)\end{array}$ & $\begin{array}{l}210.5 \\
(146-238)\end{array}$ & NS \\
\hline Smoking $(\mathrm{n} ; \%)$ & $3(10)$ & $4(14)$ & NS \\
\hline Diabetes $(\mathrm{n} ; \%)$ & $1(3)$ & $0(0)$ & NS \\
\hline
\end{tabular}

Abbreviations: ALT, anterolateral thigh; INPT, incisional negative pressure therapy; NS, nonsignificant.

\section{Results}

During the study period 58 free ALT flaps with primary closure were performed in 58 patients (study group $n=28$; control group $n=30$ ). All patients were male, with a median age of 42 years (range: 26-57 years). Median follow-up was 19 months (range: 3-78 months). There were no significant differences in age, flap size, or comorbidities between both groups $(p>0.05)$ ( - Table $\mathbf{1})$.

The global and specific complications rates among both groups are described in - Table 2. The complications were distributed over time in a similar manner throughout the study period. The global complication rate was $36.6 \%(n=11)$ in the traditional dressing group and $7.14 \%(n=2)$ in the INPT group ( $p<0.007$; - Fig. 3 ). There was a significant difference in the incidence of wound dehiscence $(p<0.028)$ and skin necrosis $(p<0.039)$ between both groups. We observed a significant risk reduction for global complications (odds ratio $[\mathrm{OR}]=0.13$; $95 \mathrm{CI}, 0.03-0.58)$, dehiscence $(\mathrm{OR}=0.17 ; 95 \mathrm{Cl}, 0.04-0.82)$ and skin necrosis ( $\mathrm{OR}=0.35 ; 95 \mathrm{CI}, 0.08-0.97$ ), in this cohort.

When stratifying patients according to flap width, no complications occurred if flap width was less than $8 \mathrm{~cm}$. Conversely in flaps, wider than $8 \mathrm{~cm}$, the incidence of complications increased in both groups being significantly lower in the study group ( $p<0.048$, - Fig. 4$)$. Multivariate logistic regression analysis showed that among all the variables studied, only the use of INPT $(\mathrm{OR}=0.21$; CI [0.06-0.63],

Table 2 Global and specific complication rates for each group $(n=58)$

\begin{tabular}{|l|l|l|l|}
\hline & $\begin{array}{l}\text { Control group } \\
(n=30) \\
(n ; \%)\end{array}$ & $\begin{array}{l}\text { INPT } \\
(n=28) \\
(n ; \%)\end{array}$ & $p$-Value \\
\hline $\begin{array}{l}\text { Global } \\
\text { complications }\end{array}$ & $11(37)$ & $2(7)$ & 0.007 \\
\hline Wound dehiscence & $9(30)$ & $2(7)$ & 0.028 \\
\hline Skin necrosis & $6(20)$ & $2(7)$ & 0.039 \\
\hline Wound infection & $2(7)$ & $1(4)$ & 0.32 \\
\hline
\end{tabular}




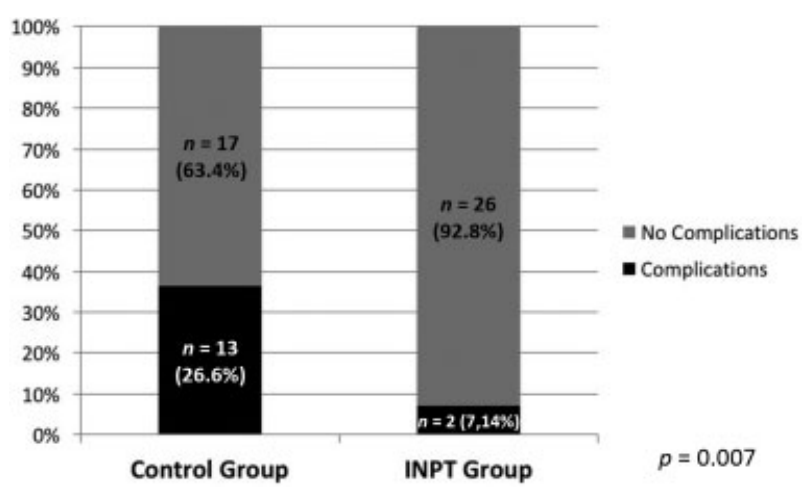

Fig. 3 Global complication rate for each group.

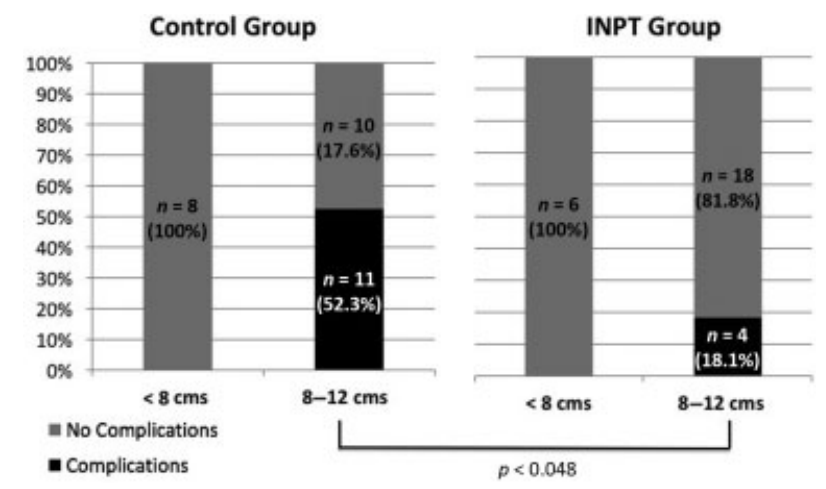

Fig. 4 Global complication rate stratified by flap width.

$p<0.008)$ and flap width $<8 \mathrm{~cm}$ had a significant relation with decreased complication rates $(\mathrm{OR}=0.54$; $\mathrm{CI}[0.03-0.86]$, $p<0.003$ ) (-Fig. 5).

\section{Discussion}

The ALT flap has an established role in the reconstruction of multiple anatomical areas. This flap has considerable advantages that explain its increasing popularity as a workhorse flap, such as an adequate pedicle length, versatility in its design, inclusion of different components if needed and also allowing to work in two teams, among many others. ${ }^{1,6,7}$

However, complications related to the donor-site may occur, especially when harvesting wide flaps. The ALT donor-site complication rates range from 11 to $21.3 \%$, with wound dehiscence being the most common complication. ${ }^{2,8-10}$ In a recent systematic review about donor-site complications following free flap, the most frequently performed flap was the ALT flap, and the most frequent complications were dehiscence (3.8\%), seroma ( $2 \%)$, and hematoma $(0.9 \%)$, being important the early treatment of the donor-site to avoid them. ${ }^{11}$ Subsequently, donor-site related morbidity may increase the length of hospital stay and related costs. ${ }^{12}$

With harvesting techniques such as Super-Thin and Suprafascial ALT flaps is possible to achieve a potential decrease in complications in the donor-site, such as muscle hernia; however, does not allow a greater number of cases with primary closure, reaching only $22.2 \%$ of primary closure in some of the studies, requiring grafting in the another cases. ${ }^{13,14}$
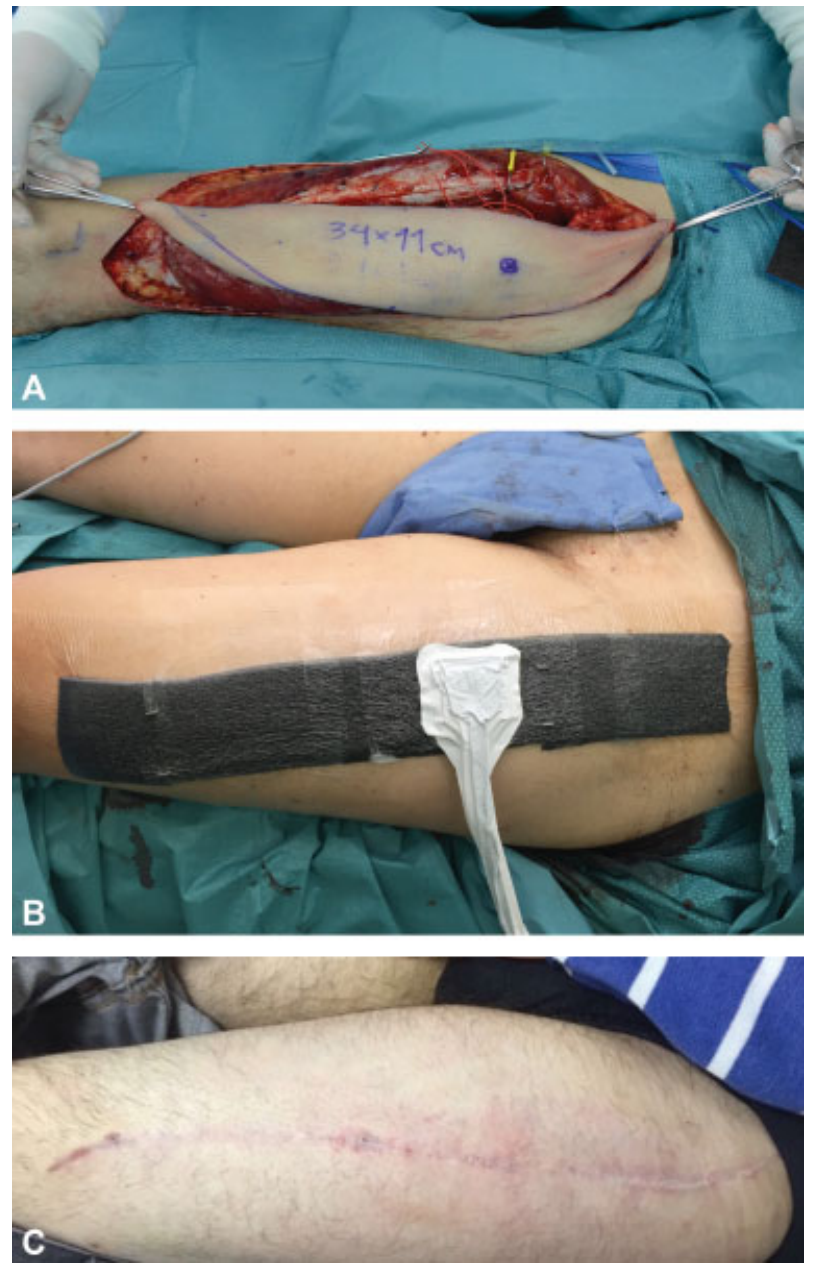

Fig. 5 Scar appearance after use of INPT. (A) ALT flap harvest $(34 \times 11 \mathrm{~cm})$. (B) Incisional negative pressure therapy. (C) Three months postoperative result. ALT, anterolateral thigh; INPT, incisional negative pressure therapy.

The use of negative pressure therapy has been recently applied as a preventive therapy in high-risk surgical wounds closed under tension, under the concept of incisional negative pressure therapy (INTP). This therapy may have several benefits, which are related to the following possible mechanisms: (1) a tension decrease across the wound edges in both the skin and the underlying tissue; (2) a compressive effect, decreasing the dead space and thus the formation of fluid collections or seromas; (3) reduction of edema and an improvement in local blood supply and isolation of the wound decreasing the chances of infection. ${ }^{3,15-18}$ All of the above may contribute to a decrease in surgical-site complications of high-risk wounds.

The use of INPT has been favorably described as a preventive treatment for donor-sites of other flaps, such as latissimus dorsi muscle, where the main concern is seroma formation, showing a decrease in the seroma incidence from 70 to $15 \%(\mathrm{OR}=0.07$; relative risk $(\mathrm{RR})=0.24) .{ }^{19}$ It has also been used on the donorsite of perforator flaps, such as the superficial circumflex iliac artery perforator flap (SCIP), where seroma and hematoma are the causative elements in wound complications. INPT was effective reducing the amount of fluid collected by suction drains, allowing its earlier removal. ${ }^{5}$ 
To the best of our knowledge, this study is the first to analyze the use of INPT in the ALT flap donor-site. In this cohort, we obtained an $80 \%$ reduction of donor-site complications when compared with standard dressings, significantly decreasing the incidence of wound dehiscence and and skin necrosis, especially for wider flaps.

We believe that operative time is not increased, since INPT is installed simultaneously while the rest of the team is completing the microsurgical procedure. The cost of the device in our center is approximately U.S.\$120 for each patient. Although, a cost analysis was not performed, it is expected that this will be beneficial, given the decrease in the complications rate, which should be associated with a reduction in hospital stay and reoperations. ${ }^{15,20}$ Furthermore, reducing postoperative complications would decrease the emotional burden on the patient, thus improving their quality of life. ${ }^{21}$

There are some limitations in this study that should be addressed. This is a retrospective cohort study and as such there was no randomized allocation of the treatment. Additionally, neither patients nor physicians are blinded to the intervention. Despite these facts, we highlight that this cohort belongs to a captive population, in which lifelong treatment is guaranteed. Consequently, patients usually have a complete and extended follow-up, in which unfavorable outcomes are precisely registered to estimate individual monetary compensation after every work-related injury.

\section{Conclusion}

In this cohort, the use of INPT reduced the morbidity after primary closure of the ALT free flap donor-site. A significant reduction in wound dehiscence and skin necrosis was observed. This therapy might prove to be a useful adjunct to prevent donor-site complications, especially after harvest of wide flaps.

\section{Disclosure}

No author had a financial interests or commercial associations that pose or create a conflict of interest for this study.

\section{References}

1 Wei FC, Jain V, Celik N, Chen HC, Chuang DC, Lin CH. Have we found an ideal soft-tissue flap? An experience with 672 anterolateral thigh flaps. Plast Reconstr Surg 2002;109(07):2219-2226, discussion 2227-2230

2 Collins J, Ayeni O, Thoma A. A systematic review of anterolateral thigh flap donor site morbidity. Can J Plast Surg 2012;20(01):17-23

3 Webster J, Scuffham P, Stankiewicz M, Chaboyer WP. Negative pressure wound therapy for skin grafts and surgical wounds healing by primary intention. Cochrane Database Syst Rev 2014;(10):CD009261
4 Kim DY, Park SJ, Bang SI, Mun GH, Pyon JK. Does the use of incisional negative-pressure wound therapy prevent mastectomy flap necrosis in immediate expander-based breast reconstruction? Plast Reconstr Surg 2016;138(03):558-566

5 Peter Suh HS, Hong JP. Effects of incisional negative-pressure wound therapy on primary closed defects after superficial circumflex iliac artery perforator flap harvest: randomized controlled study. Plast Reconstr Surg 2016;138(06):1333-1340

6 Song YG, Chen GZ, Song YL. The free thigh flap: a new free flap concept based on the septocutaneous artery. Br J Plast Surg 1984; 37(02):149-159

7 Ali RS, Bluebond-Langner R, Rodriguez ED, Cheng MH. The versatility of the anterolateral thigh flap. Plast Reconstr Surg 2009;124(6, Suppl):e395-e407

8 Townley WA, Royston EC, Karmiris N, Crick A, Dunn RL. Critical assessment of the anterolateral thigh flap donor site. J Plast Reconstr Aesthet Surg 2011;64(12):1621-1626

9 Hanasono MM, Skoracki RJ, Yu P. A prospective study of donor-site morbidity after anterolateral thigh fasciocutaneous and myocutaneous free flap harvest in 220 patients. Plast Reconstr Surg 2010;125(01):209-214

10 Purnell CA, Lewis KC, Mioton LM, et al. Donor-site morbidity of medial and lateral thigh-based flaps: a comparative study. Plast Reconstr Surg Glob Open 2016;4(11):e1012

11 Lakhiani C, DeFazio MV, Han K, Falola R, Evans K. Donor-Site morbidity following free tissue harvest from the thigh: a systematic review and pooled analysis of complications. J Reconstr Microsurg 2016;32(05):342-357

12 Shanmugam VK, Fernandez SJ, Evans KK, et al. Postoperative wound dehiscence: Predictors and associations. Wound Repair Regen 2015;23(02):184-190

13 Seth AK, Iorio ML. Super-thin and suprafascial anterolateral thigh perforator flaps for extremity reconstruction. J Reconstr Microsurg 2017;33(07):466-473

14 Hong JP, Choi DH, Suh H, et al. A new plane of elevation: the superficial fascial plane for perforator flap elevation. J Reconstr Microsurg 2014;30(07):491-496

15 Horch RE. Incisional negative pressure wound therapy for highrisk wounds. J Wound Care 2015;24(4, Suppl)21-28

16 Scalise A, Calamita R, Tartaglione C, et al. Improving wound healing and preventing surgical site complications of closed surgical incisions: a possible role of Incisional negative pressure wound therapy. a systematic review of the literature. Int Wound J 2016;13(06):1260-1281

17 Suh H, Lee AY, Park EJ, Hong JP. Negative pressure wound therapy on closed surgical wounds with dead space: animal study using a swine model. Ann Plast Surg 2016;76(06):717-722

18 Schmedes GW, Banks CA, Malin BT, Srinivas PB, Skoner JM. Massive flap donor sites and the role of negative pressure wound therapy. Otolaryngol Head Neck Surg 2012;147(06):1049-1053

19 Angspatt A, Laopiyasakul T, Pungrasmi P, Suwajo P. The role of negative-pressure wound therapy in latissimus dorsi flap donor site seroma prevention: a cohort study. Arch Plast Surg 2017;44(04): 308-312

20 Sandy-Hodgetts K, Leslie GD, Lewin G, Hendrie D, Carville K. Surgical wound dehiscence in an Australian community nursing service: time and cost to healing. J Wound Care 2016;25(07):377-383

21 Corrêa NF, de Brito MJ, de Carvalho Resende MM, et al. Impact of surgical wound dehiscence on health-related quality of life and mental health. J Wound Care 2016;25(10):561-570 